\title{
Effect of different restorative crown design and materials on stress distribution in endodontically treated molars and peripheral bone: A finite element analysis study
}

Jie Lin ( $\square$ linjie.dds@gmail.com )

Fujian Medical University

Zhenxiang Lin

Hospital of Fujian Provincial Authorities

Zhiqiang Zheng

Fujian Medical University

\section{Research article}

Keywords: finite element analysis, endocrown, post-core crown, fiber post, zirconia

Posted Date: December 30th, 2019

DOl: https://doi.org/10.21203/rs.2.19592/v1

License: (c) (i) This work is licensed under a Creative Commons Attribution 4.0 International License.

Read Full License 


\section{Abstract}

Background: The purposes of this simulation study were to evaluate the stresses in the roots of endodontically treated molars with extensive coronal tissue loss which were restored by endocrowns (allin-one core and crown) and traditional crowns with post-cores, during masticatory simulation using finite element analysis.

Methods: A mesio-distal cross-section of a lower right first molar was digitized and used to create 2dimensional models of the teeth and supporting tissue; different crown designs, viz ., endocrown with 2 $\mathrm{mm}$ occlusal clearance, endocrown with $4 \mathrm{~mm}$ occlusal clearance and post-core crown; different crown materials, viz ., zirconia (Zr) and lithia-disilicate reinforced glass ceramic (LDRGC), and different post and core materials, viz. , glass fiber (GF), stainless steel (SS) and metal cast (MC). A simulated $100 \mathrm{~N}$ vertical occlusal load was applied to the distal marginal ridge of the crown.

Results: The root canal inner wall stresses of SS post (maximum $33.7 \mathrm{MPa}$ ) and $\mathrm{MC}$ post (maximum 36.3 MPa) were higher than that of GF post (maximum 19.1 MPa) and endocrown (maximum 8.9 MPa).

Conclusion: Endocrown showed reduced stresses at its root canal inner wall but increased stresses at the coronal cavity inner wall when compared to post-core crowns.

\section{Background}

The decision of how to rehabilitate endodontically treated molars (ETM) with extensive loss of coronal structure is a challenge in restorative dentistry. Coronal tooth tissue is often significantly damaged after endodontic treatment and are traditionally restored with metal posts and cores and prosthetic crowns $(1-3)$. Initially, it was believed that this procedure would provide better reinforcement of the remaining dental structure $(4,5)$. However, it has been observed that the use of intracanal retainers only help in the retention of the prosthetic crown. As a result of removing a dental structure to enable the placement of rigid dental materials devoid of mechanical behaviors similar to those of the tooth, the remaining tooth is weakened ${ }^{(6)}$. The preparation of a molar for a post in relatively narrow root canals also involves a risk of accidental root perforation and fracture ${ }^{(7)}$.

In fact, minimally invasive preparations, with maximal tissue conservation, are now considered 'the gold standard' for restoring ETM ${ }^{(8)}$. In 1995, the endocrown was described by Pissis who is the forerunner of the endocrown technique, as the 'mono-block porcelain technique' ${ }^{(9)}$. Currently, due to the advances in adhesive methods and materials, endocrown type of intracoronal restorations were suggested for damaged posterior teeth as an alternative to post and core retained ones ${ }^{(10)}$. It is a method particularly indicated in cases in which there is excessive loss of hard tissues of the crown, interproximal space is limited, and traditional post-core crown is not possible because of inadequate ceramic thickness ${ }^{(11)}$. Their advantages include the fact that tooth structures require little preparation, ease of preparation, demand less clinical time when compared with conventional crowns ${ }^{(12,13)}$. 
Knowledge of the stress distribution within and around the roots is a key factor for understanding root fracture, which are well-known problems with ETMs. It has been proposed that molars restored with

endocrowns are less prone to fracture than those with posts ${ }^{(14,15)}$. Nevertheless, so far there was no clear evidence to prove it. Dejak et al. ${ }^{(16)}$ compared equivalent stresses in molars restored with endocrowns as well as posts and cores during masticatory simulation using finite element analysis (FEA) and found the tensile stresses achieved were 4 times higher values than under endocrowns. These tensile stresses occurred in the dentin under the crown shoulder, rather than in the root. A similar study by Lin et al. ${ }^{(15)}$ showed that the stress values on the dentin and luting cement for the endocrown restoration were lower than those for the crown. However, these studies made no attempt to compare endocrowns and post-core crowns. Moreover, relatively little is known about the differences of stress distribution in the roots.

The type of restoration (endocrown or post-core crown, different crown and post materials) will provide rational stress distribution and reduce a risk of fracture in molars? Because of the absence of information about the biomechanical behavior of endocrowns and the expectation that this type of restoration would behave similarly or superiorly to post-core crowns, the present study has aims to evaluate the von Mises stresses in the roots of ETMs with extensive coronal loss, restored by endocrowns and post-core crowns, during masticatory simulation using FEA, and simulate stresses at the first molar made with different crown and post materials.

\section{Methods}

\section{Structures and geometric conditions of the computer aided design (CAD) model}

A mesio-distal cross-section of a lower right first molar was digitized and used to create 2-dimensional (2D) models. There were three different model designs (Fig 1), viz., endocrown with $2 \mathrm{~mm}$ occlusal clearance, endocrown with $4 \mathrm{~mm}$ occlusal clearance and post-core crown. The restorations used two different crown materials, viz., zirconia ( $\mathrm{Zr}$ ) and lithia-disilicate reinforced glass ceramic (LDRGC), and three different post and core materials, viz., glass fiber (GF), stainless steel (SS) and metal cast (MC). There were ten kinds of combination in this study.

Endocrown-2 mm-Zr: full zirconia endocrown with $2 \mathrm{~mm}$ occlusal clearance;

Endocrown-2 mm- LDRGC: full lithia-disilicate reinforced glass ceramic endocrown with $2 \mathrm{~mm}$ occlusal clearance;

Endocrown-4 mm-Zr: full zirconia endocrown with $4 \mathrm{~mm}$ occlusal clearance;

Endocrown-4 mm- LDRGC: full lithia-disilicate reinforced glass ceramic endocrown with $4 \mathrm{~mm}$ occlusal clearance;

GF post-Zr: glass fiber post + full zirconia crown;

GF post- LDRGC: glass fiber post + full lithia-disilicate reinforced glass ceramic crown; 
SS post-Zr: stainless steel post + full zirconia crown;

SS post- LDRGC: stainless steel post + full lithia-disilicate reinforced glass ceramic crown;

MC post-Zr: metal cast post + full zirconia crown;

MC post- LDRGC: metal cast post + full lithia-disilicate reinforced glass ceramic crown.

In the GF posts and SS posts, the cores were made of composite, while in the MC posts they were made of metal. The model was created from radiographic image of a real tooth (Fig. 1a) using a FEA software (ANSYS v. 10; ANSYS Inc., Canonsburg, PA, USA) ${ }^{(17) .}$

\section{Endocrown and post-core crown designs}

The Endocrown-2 $\mathrm{mm}$ designs were created with 2.0 occlusal clearance, $7.0 \mathrm{~mm}$ cavity depth, and 5.3 $\mathrm{mm}$ base width. The prepared cavity walls tapered with 2-5 degrees from the cavity base to the cavosurface (Fig. 1b). The Endocrown-4 mm designs were created with 4.0 occlusal clearance, $5.0 \mathrm{~mm}$ cavity depth, $5.3 \mathrm{~mm}$ base width and 2-5 degrees cavity walls taper (Fig. 1c). Jacket crown preparations were created with $2.0 \mathrm{~mm}$ occlusal clearance, $0.5-1.5 \mathrm{~mm}$ cervical clearance and shoulder margin, 2-5 degrees tapering angle for first molars, $14.0 \mathrm{~mm}$ post lengths. Rounded shoulder margins and anatomic occlusal reduction were incorporated in model (Fig. 1d).

The surrounding bone was modeled as cortical bone $(1.5 \mathrm{~mm}$ thickness) and cancellous bone, which were assumed to be isotropic, homogeneous, and linearly elastic. A $0.2 \mathrm{~mm}$ periodontal ligamentwas modeled around the roots. A $0.1 \mathrm{~mm}$ thick cement-imitating layer was formed around the root part of the created post and under the crown. Perfect bonding was assumed at all the interfaces, including those between the teeth, the cores, the crowns, the posts and bones.

\section{Material properties, mesh generation and boundary conditions}

The elastic moduli and Poisson's ratios of the materials used are shown in Table 1. Material properties were assumed to be isotropic, homogenous, and linear-elastic, except the GF post. The material of GF post was anisotropic (Young's modulus along its long axis was $38.5 \mathrm{GPa}$, and 12.0 GPa perpendicular to that axis).

For calculation purposes, each tooth model was divided into 2-D 4-node structural solid elements (PLANE42). This element is defined by four nodes having two degrees of freedom at each node: translations in the nodal $x$ and $y$ directions. In model with endocrown- $2 \mathrm{~mm}, 4,596$ elements joined at 4,701 nodes were used. In model with endocrown-4 mm, 4,582 elements joined at 4,693 nodes were used. In model with post-core crown, 4,657 elements joined at 4,759 nodes were used. The aim of this preliminary FEA was to identify the most highly stressed regions within the restoration, especially those along the distal root inner and outer surface. These would be the regions to which shape optimization 
would be applied. Thus, the mesh around the distal root inner and outer surface was made much finer than those in the other areas, with an average element edge length of $0.2 \mathrm{~mm}$.

Fixed zero-displacement in both the horizontal and vertical directions was defined at the horizontal and vertical cut-planes of the supporting bone. A load was applied that corresponded to static loading, assuming no vibrational or dynamic effects in the structure. To reflect the stress distribution at the moment of equilibrium, a simulated $100 \mathrm{~N}$ vertical occlusal load was applied to the distal marginal ridge. The von Mises stress values were calculated by FEA along the distal root canal inner wall and the root outer surface (Fig 1: $A \rightarrow B \rightarrow C$ ). We focused on the distal root canal inner wall because the post was set in the distal root canal, from preliminary analysis the distal root canal inner wall was analyzed in greater detail. The stress distribution within the tooth/restoration cross-section was solved with the FEA software (ANSYS).

\section{Results}

The von Mises stress analysis for the 2 crown designs, 2 crown materials, 3 post materials tested is presented in Fig. 2. The stress distributions were similar for 2 different crown materials ( $\mathrm{Zr}$ and LDRGC) and 2 different occlusal clearance $(2 \mathrm{~mm}$ and $4 \mathrm{~mm}$ ). The crown stresses of $Z$ r were more concentrated. For the endocrown-2 mm-Zr and endocrown-4 mm-Zr (Fig. 2), a stress peak was found at the distal cavity inner wall (maximum 27.7 MPa and 17.8 MPa). Compared with the endocrown-2 mm, the endocrown$4 \mathrm{~mm}$ reduced the stress concentration in crown.

For the post-core crown, the main difference was found at the distal root. The low elastic modulus of the GF post showed reduced the von Mises stresses (maximum $23.6 \mathrm{MPa}$ ) (Fig. $2 \mathrm{GF}$ post); both the SS post (maximum $62.9 \mathrm{MPa}$ ) and $\mathrm{MC}$ post (maximum $67.5 \mathrm{MPa}$ ) ensure a stress concentration at the post and distal root.

Differences also were found in the stresses at the alveolar bones. The endocrown showed increased and smooth stresses in the periodontal support tissue (maximum 24.2 MPa). (Fig. 2). The plots of the postcore crowns displayed only minor differences between post materials, $20.1 \mathrm{MPa}$ for GF post, 17.4 MPa for SS post and16.6 MPa for MC post.

Figure 3 shows the path plots of the interfacial von Mises stresses along the distal root canal inner wall and the root outer surface $(A \rightarrow B \rightarrow C)$ in endocrown and post-core crown. No difference was found in the $\mathrm{Zr}$ crowns and the LDRGC crowns in the path plots. In the endocrown covered tooth, maximum von Mises stress values of $9 \mathrm{MPa}$ were recorded in the distal root canal inner wall. The root canal inner wall stresses of SS post (maximum 33.7 MPa) and MC post (maximum 36.3 MPa) were higher than that of GF post (maximum 19.1 MPa) and endocrown (maximum 8.9 MPa). The behavior of the endocrown clearly differed from that of the post-core crowns. The endocrown only had one peak, nevertheless the post-core crowns had two peaks. The peak 1 was caused by the apical foramen, and the peak 2 was caused by the tip of the post. von Mises stress values around the SS and MC post tip (Peak 2) reached 12.7 MPa and

14.1 MPa. They were higher than that of GF post (7.5 MPa). In the same region, von Mises stress of 
endocrown achieved a value of $5 \mathrm{MPa}$. The endocrown showed higher stresses occurred in the root outer surface than that of post-core crowns.

\section{Discussion}

The numeric FEA modeling is able to reveal the otherwise inaccessible stress distribution within the toothrestoration complex. It has proven to be an important tool in the design process for the understanding of tooth biomechanics and the biomimetic approach $(27,28)$. Although teeth are 3-D structures, important mechanical events in endocrown and post-core crown appear within the mesio-distal plane ${ }^{(27,29)}$. These events support the use of the 2-D plane-strain model for numerical analyses. Volume meshing of 3-D teeth structures is usually restricted to tetrahedral elements. The tetrahedral element has a good ability to model irregular shapes; however, its accuracy is poor for bending and shearing dominated problems. The use of a 2-D model is also valuable because of its improved performance in terms of element number and simulation quality. Consequently, 2-D analysis was chosen in this study.

Inversely to anterior teeth, posterior cusps do not deform under load as simple cantilever beams $(30,31)$. The deformation mode is complicated by the numerous possibilities in the application of loads. It is inevitable for the molar to receive non-axial force in the process of occlusion. The load configuration applied in this study was selected because it creates a maximum challenge for distal root flexure, which seems to represent an important biomechanical feature of post-core crown. Mean masticatory forces have been reported by Anderson ${ }^{(32)}$ to be in the range of 70.6 to $146.1 \mathrm{~N}$. Thus, the applied $100 \mathrm{~N}$ load lies within the range of these values in this study, and it has been used in a number of FE model validation studies ${ }^{(33)}$.

Despite great variations in crown material properties, there were only minor differences in the alveolar bone. For a given load configuration, it appears that overall stress distribution within the tooth-bone complex was more influenced by geometry design of restoration (endocrown vs. post-core crown) than by composition (e.g. crown, post and core restorative material type). The endocrown showed a relatively smooth stress distribution in the root and the periodontal support tissue. This is largely due to two reasons: firstly, post-core crown applied extra-coronal retainer, while endocrown used intra-coronal retainer. Endocrown with intra-coronal retainer was more conducive to transfer the force to the wall of the pulp chamber and the periodontal tissue, rather than to the root canal wall. Secondly, endocrown geometrically reduced the rotation center of the crown restoration in comparison with the full crown (Fig. 1, Ring arrow). This also contributed to transfer the occlusal force to periodontal tissue.

The root canal after instrumentation (root canal or post preparation) is thinner and weaker than the rest of the tooth. Stress concentration at the tip of the post must therefore be regarded as most harmful. It is precisely in the area of concentrated stresses where differences were found (Fig. 3, Peak 2 of SS post and $M C$ post). e.g. stresses in the tip of the post around MC posts achieved 3 times higher values than under endocrowns and twice higher values than under GF posts. In this specific zone, low-elastic modulus restorative materials showed reduced stresses, which can be explained by the stress redistribution into 
the more flexible GF post and composite core. Stress concentration of endocrown in the root canal was relatively small, it is good to avoid the weak tip of the post. The molar post-core crown increased the risk of accidental root fracture. The highest von Mises stresses in the distal root canal occurred in molar restored with SS and MC posts. These types of restorations seem to be the least beneficial in molar teeth. Biac-chi and Basting ${ }^{\left({ }^{34}\right)}$ found that molars with endocrowns are more fracture resistant than teeth restored with GF posts and cores and ceramic crowns. Taking into consideration the suitable stress distribution of endocrowns, minimal invasive preparation of tooth structures and no roots damage, these restorations can be recommended to use in molars.

Although von Mises stress levels in the root and the periodontal tissue of molars restored with post-core crowns were higher than stress levels in the tooth with the endocrown. $\mathrm{Zr}$ endocrown represented the one condition with a slightly greater amount of stresses concentration in the distal cavity inner wall when compared to the post-core crowns. Thus, this is regarded as a potential threat, knowing that remaining coronal tooth structure fractured. On the other hand, experimental strength study by Forberger and

Göhring ${ }^{(35)}$, have shown no significant differences between teeth restored with posts and endocrowns in terms of fracture resistance. Under the analytical conditions of this study, the results were largely dependent on the Young's modulus and Poisson ratio of the materials. However in reality there will be other dominating factors such as the bond strength, potential for micro-crack at the interface, fatigue damage potentials both for the hard tissues and the restorative materials. Further experimental studies and clinical trials are needed to validate the results of this FEA study.

\section{Conclusions}

In conclusion, posterior ceramic endocrowns bonded to the tooth substrate is ajudicious way to reduce excessive tooth tissue removal and surgical crown lengthening. Within the limitations of this FEA experiment, it can be concluded that: Endocrown showed reduced stresses at its root canal inner wall but increased stresses at the coronal cavity inner wall when compared to post-core crowns. Endocrown exhibited higher stresses occurred at the root outer surface, while post-core crowns showed increased stresses at the root canal inner wall, especially SS post and MC post. The stress distributions in root were similar for 2 different crown materials (zirconia and lithia-disilicate reinforced glass ceramic) and 2 different occlusal clearance ( $2 \mathrm{~mm}$ and $4 \mathrm{~mm}$ ).

\section{Abbreviations}

Zr: zirconia, LDRGC: lithia-disilicate reinforced glass ceramic, GF: glass fiber, SS: stainless steel, MC: metal cast, ETM: endodontically treated molars, FEA: finite element analysis, CAD: computer aided design

\section{Declarations}

\section{Ethics approval and consent to participate}


Not applicable

\section{Consent for publication}

Not applicable

\section{Availability of data and material}

The complete data and materials described in the research article are freely available from the corresponding author on reasonable request.

\section{Competing interests}

The authors have no conflicts of interest relevant to this article.

\section{Funding}

This work was supported by the Fujian province science and technology innovation joint fund project (Grant No. 2017Y9095) and the Health and family planning commission of the Fujian province, youth research project (Grant No. 2016-1-25).

\section{Authors' contributions}

$\mathrm{JL}$ and $\mathrm{ZZ}$ conceived and designed the study. JL performed the finite element analysis. JL and ZL wrote the paper. ZZ reviewed and edited the manuscript. All authors read and approved the final manuscript.

\section{Acknowledgements}

The study design and the operation of the finite element analysis were supported by Prof. Shinya Akikazu.

\section{References}

1. Dartora NR, de Conto Ferreira MB, Moris ICM, et al. Effect of Intracoronal Depth of Teeth Restored with Endocrowns on Fracture Resistance: In Vitro and 3-dimensional Finite Element Analysis. J Endod. 2018;44;1179-85.

2. Schlichting LH, Resende TH, Reis KR, Magne P. Simplified treatment of severe dental erosion with ultrathin CAD/CAM composite occlusal veneers and anterior bilaminar veneers. J Prosthet Dent 2016;116;474-82.

3. Rocca GT, Rizcalla N, Krejci I. Fiber-reinforced resin coating for endocrown preparations: a technical report. Oper Dent 2013;38;242-8.

4. Valdivia ADCM, Rodrigues MP, Bicalho AA, et al. Biomechanical Effect of Ferrule on Incisors Restored with a Fiberglass Post and Lithium-Disilicate Ceramic Crown after Thermal Cycling and Fatigue Loading. J Adhes Dent. 2018;20;133-42. 
5. Ferrari M, Sorrentino R, Juloski J, et al. Post-Retained Single Crowns versus Fixed Dental Prostheses: A 7-Year Prospective Clinical Study. J Dent Res. 2017;96(13):1490-7.

6. Soares CJ, Santana FR, Silva NR, Preira JC, Pereira CA. Influence of the endodontic treatment on mechanical properties of root dentin. J Endod 2007;33;603-6.

7. Ferrari M, Vichi A, Grandini S. Efficacy of different adhesive techniques on bonding to root canal walls: an SEM investigation. Dent Mater 2001;17;422-9.

8. Dietschi D, Duc O, Krejci I, Sadan A. Biomechanical considerations for the restoration of endodontically treated teeth: A systematic review of the literature, part ii (evaluation of fatigue behavior, interfaces, and in vivo studies). Quintessence Int 2008;39;117-29.

9. Pissis P. Fabrication of a metal-free ceramic restoration utilizing the monobloc technique. Pract Periodontics Aesthet Dent 1995;7;83-94.

10. Shin Y, Park S, Park JW, Kim KM, Park YB, Roh BD. Evaluation of the marginal and internal discrepancies of CAD/CAM endocrowns with different cavity depths: An in vitro study. J Prosthet Dent 2016;117;109-15.

11. Gaintantzopoulou MD, El-Damanhoury HM. Effect of Preparation Depth on the Marginal and Internal Adaptation of Computer-aided Design/Computer-assisted Manufacture Endocrowns. Oper Dent 2016;41;607-16.

12. Gresnigt MM, Özcan $M$, van den Houten $M L$, Schipper $L$, Cune MS. Fracture strength, failure type and Weibull characteristics of lithium disilicate and multiphase resin composite endocrowns under axial and lateral forces. Dent Mater 2016;32;607-14.

13. Rocca GT, Saratti CM, Poncet A, Feilzer AJ, Krejci I. The influence of FRCs reinforcement on marginal adaptation of CAD/CAM composite resin endocrowns after simulated fatigue loading. Odontology 2016;104;220-32.

14. El-Damanhoury HM, Haj-Ali RN, Platt JA. Fracture resistance and microleakage of endocrowns utilizing three CAD-CAM blocks. Oper Dent 2015;40;201-10.

15. Lin CL, Chang YH, Chang CY, Pai CA, Huang SF. Finite element and Weibull analyses to estimate failure risks in the ceramic endocrown and classical crown for endodontically treated maxillary premolar. Eur J Oral Sci 2015;118;87-93.

16. Dejak B, Młotkowski A. 3D-Finite element analysis of molars restored with endocrowns and posts during masticatory simulation. Dent Mater 2013;29;e309-17.

17. Zienkiewicz O, Tylor R, editors. Finite element method. The Basis, 1, 5th ed. Oxford: ButterworthHeinemann 2000;87-110.

18. Habelitz S, Marshall S, Marshall G, Balooch M. Mechanical properties of human dental enamel on the nanometre scale. Arch Oral Biol 2001;46;173-83.

19. Craig R, Peyton F. Elastic and mechanical properties of human dentin. J Dent Res 1958;37;710-8.

20. Friedman CM, Sandrik JL, Heuer MA, Rapp GW. Composition and mechanical properties of guttapercha endodontic points. J Dent Res 1975;54;921-5. 
21. Borchers $L$, Reichart $P$. Three-dimensional stress distribution around a dental implant at different stages of interface development. J Dent Res 1983;62;155-9.

22. Lin J, Shinya A, Gomi H, Shinya A. Finite element analysis to compare stress distribution of connector of lithia-disilicate reinforced glass ceramic and zirconia based fixed partial denture. Odontology 2012;100;96-9.

23. Jie L, Shinya A, Lassila LV, Vallittu PK. Composite resin reinforced with pre-tensioned fibers: a threedimensional finite element study on stress distribution. Odontology 2013;101;29-33.

24. Morris HF. The mechanical properties of metal ceramic alloys as cast and after simulated porcelain firing. J Prosthet Dent 1989;61;160-9.

25. Lanza A, Aversa R, Rengo S, Apicella D, Apicella A. 3D FEA of cemented steel, glass and carbon posts in a maxillary incisor. Dent Mater 2005;21;709-15.

26. Pegoretti A, Fambri L, Zappini G, Bianchetti M. Finite element analysis of a glass fibre reinforced composite endodontic post. Biomaterials 2002;23;2667-82.

27. Zheng Z, Lin J, Shinya A, Matinlinna JP, Botelho MG, Shinya A. Finite element analysis to compare stress distribution of gold alloy, lithium-disilicate reinforced glass ceramic and zirconia based fixed partial denture. J Investig Clin Dent 2012;3;291-7.

28. Lin J, Zheng Z, Shinya A, Matinlinna JP, Botelho MG, Shinya A. Structural stability of posterior retainer design for resin-bonded prostheses: a 3D finite element study. Odontology 2015;103;333-8.

29. Chuang SF, Yaman P, Herrero A, Dennison JB, Chang CH. Influence of post material and length on endodontically treated incisors: an in vitro and finite element study. J Prosthet Dent 2010;104;379-88.

30. Jantarat J, Panitvisai P, Palamara JE, Messer HH. Comparison of methods for measuring cuspal deformation in teeth. J Dent 2001;229;75-82.

31. Magne $M$, Belser U. Rationalization of shape and related stress distribution in posterior teeth: A finite element study using nonlinear contact analysis. Int J Periodontics Restorative Dent 2002;22;425-33.

32. Anderson DJ. Measurement of stress in mastication. I. J Dent Res 1956;35, 664-70.

33. Lin J, Matinlinna JP, Shinya A, Botelho MG, Zheng Z. Effect of fiber post length and abutment height on fracture resistance of endodontically treated premolars prepared for zirconia crowns. Odontology. 2018;106;215-22.

34. Biacchi GR, Basting RT. Comparison of fracture strength of endocrowns and glass fiber post-retained conventional crowns. Oper Dent 2012;37;130-6.

35. Forberger N, Göhring TN. Influence of the type of post andcore on in vitro marginal continuity, fracture resistance, and fracture mode of lithia disilicate-based all-ceramic crowns. J Prosthet Dent 2008;100;264-73.

\section{Table}

Table 1 Properties of restorative materials and tooth tissue. 


\begin{tabular}{lcc}
\hline & Young's modulus (GPa) & Poisson ratio \\
\hline Enamel & $84^{(18)}$ & $0.33^{(18)}$ \\
\hline Dentin & $18.6^{(19)}$ & $0.31^{(19)}$ \\
Gutta-percha & $0.14^{(20)}$ & $0.45^{(20)}$ \\
\hline Periodontium & $0.05^{(16)}$ & $0.45^{(16)}$ \\
\hline Cortical bone/ Cancellous bone & $13.7 / 1.37^{(21)}$ & $0.3^{(21)}$ \\
\hline Luting resin cement & $8.3^{(16)}$ & $0.35^{(16)}$ \\
\hline LDRGC & $96^{(22)}$ & $0.23^{(22)}$ \\
\hline Zirconia & $205^{(22)}$ & $0.19^{(22)}$ \\
\hline Glass fiber post: & $38.5 / 12^{(23)}$ & $0.35 / 0.11^{(23)}$ \\
\hline Fiber_longitudinal/ Fiber_transverse & & $0.33^{(26)}$ \\
\hline Metal cast post $\square \mathrm{Ni-Cl} \square$ & $188^{(24)}$ & $0.33^{(24)}$ \\
\hline Stainless steel post & $210^{(25)}$ & $0.3^{(25)}$ \\
\hline Composite resin core & & \\
\hline
\end{tabular}

LDRGC: lithia-disilicate reinforced glass ceramic

\section{Figures}
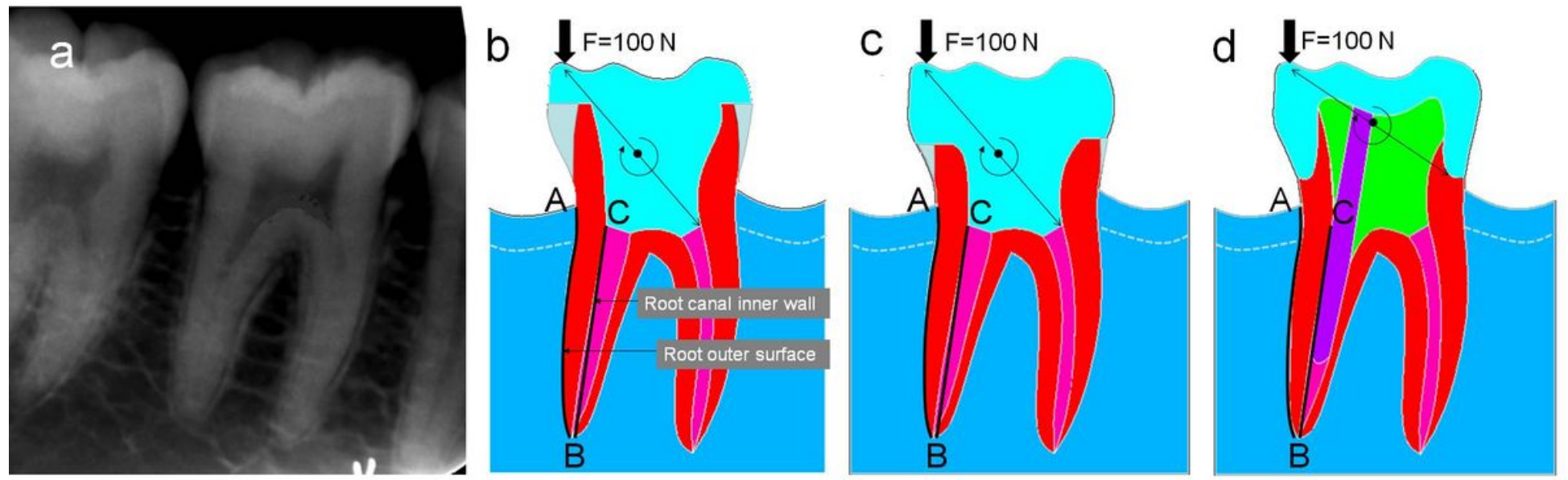

Figure 1 
2-D models of first mandibular molar tooth with roots and periodontium (bucco -lingual side view). Original contours developed from radiographic image of first mandibular molar tooth. (a) radiographic image of first mandibular molar tooth, (b) endocrown, (c) post-core crown. Thick arrow: simulated $100 \mathrm{~N}$ vertical occlusal load. $A B$ and $B C$ : distal root outer surface and distal root canal inner wall. Ring arrow: rotation center. Endocrown geometrically reduced the rotation center of the crown restoration in comparison with the full crown.
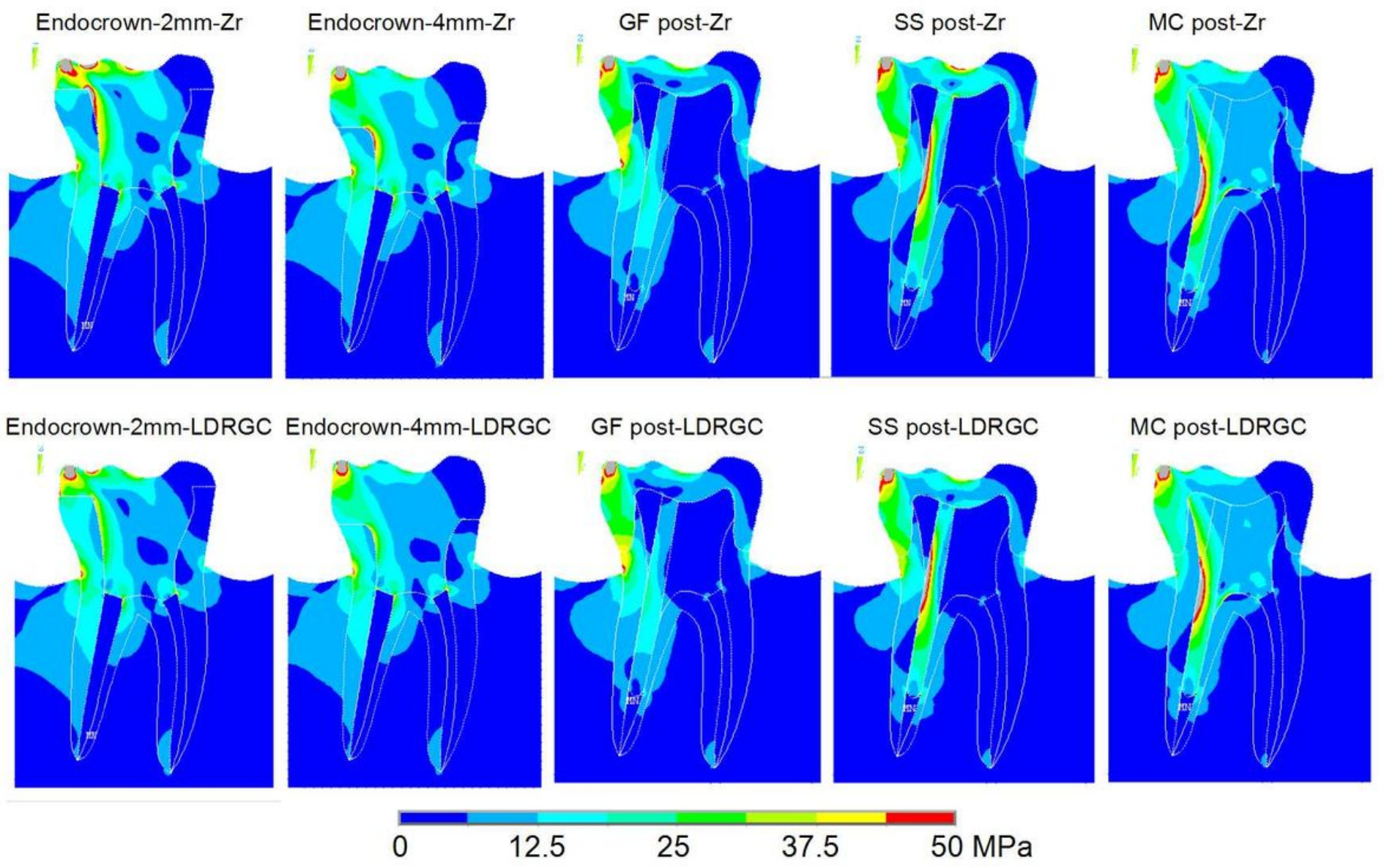

\section{Figure 2}

von Mises stress distribution maps in FE analysis results. Color bar indicates range of 0 to $50 \mathrm{MPa}$. 


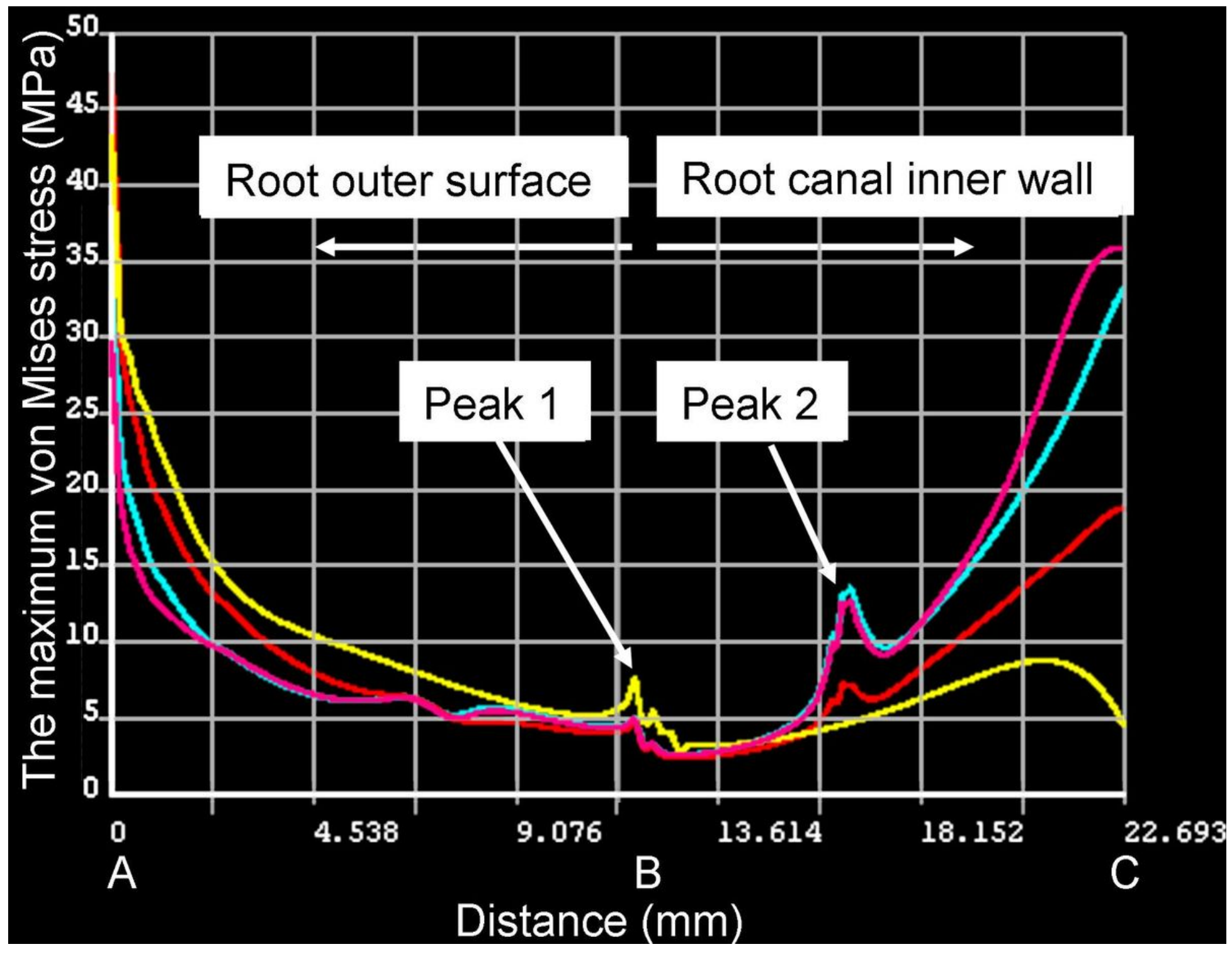

Figure 3

The path plots of the interfacial von Mises stress along the distal root canal inner wall and the root outer surface $(A \rightarrow B \rightarrow C)$. Blue line: SS post-Zr and SS post-LDRGC; Pink line: MC post-Zr and MC post-LDRGC; Red line: GF post-Zr and GF post-LDRGC; Yellow line: endocrown-2mm-Zr, endocrown-2mm-LDRGC, endocrown-4mm-Zr and endocrown-4mm-LDRGC. Peak 1: apical foramen; Peak 2: tip of post. 